\title{
Analysis of Knowledge Push Technology Platform of Library and Information Institutions
}

\author{
Hui Wang \\ University Library, Jilin Agricultural University, 130118 Changchun, PR China \\ E-mail.13104452100@163.com
}

\begin{abstract}
Under the premise that the knowledge push technology platform as the operational strategy of Library and Information Institutions, the paper analyzes the value of knowledge push service platform seriously and comprehensively, and analyzes the factors that affect the realization of the value model of knowledge push service platform. Meanwhile, it also introduces from the five main parts of value chain, which are value proposition, value analysis, value transmission, value network and value realization and puts forward the evaluation and improvement mechanism and the supporting system which are related to the knowledge push technology platform of the Library and Information Institution.
\end{abstract}

Keywords-The Library and Information Institution; Push service; Push technology; Operational strategy; Value analysis; Value transmission; Influence factors.

\section{INTRODUCTION}

In the present society, which has a great desire for knowledge, to build a bridge between the knowledge and its pursuit is the main purpose of the knowledge push technology platform of the Library and Information Institution.

\section{THE BACKGROUND OF THE FORMATION OF THE KNOWLEDGE PUSH TECHNOLOGY PLATFORM OF THE LIBRARY AND INFORMATION INSTITUTIONS.}

With the continuous development of social economy, the development of enterprises in the era of knowledge economy has changed, the traditional resources such as labor, capital and natural resources are not the first choice, but knowledge has become the most valuable asset and the key to win the competition. In addition, in the background of rapid development of network technology and computer technology, the main channel for the enterprise to acquire knowledge is to get through the network, so the "knowledge management" in the network environment has also gained the opportunity to keep up. But there are many drawbacks in the process of acquiring knowledge from the network. For example, it often occurs that some members' knowledge needs cannot be met when the organization carry out some new innovative activities or make some decisions. There are two main reasons: first, the organization has the knowledge that members need, but because they do not understand the members' specific needs of knowledge, and therefore they cannot provide the knowledge and service that the members need to them timely and accurately; the second is that the members desire to get the support of related knowledge while conducting some certain innovative activities or decision-making, but they has not got the required knowledge limited to the access to knowledge and their own search ability. Therefore, from the above two main reasons, there is a lack of a connection between the knowledge and the needs, but not because of the lack of knowledge itself. It is only short of a reasonable and scientific bridge to transfer the knowledge. And precisely in this context, the knowledge push came into being, which provides a possibility of the timely and reliable knowledge transmission and knowledge service, and in a certain extent, the asymmetric phenomenon of knowledge can be reduced, and it is also conducive to the renewal and application of knowledge. Therefore, the knowledge push platform is to carry out a comprehensive knowledge push function with the computer system, to provide the appropriate knowledge resources after the accurate positioning of the members' knowledge demands.

\section{How to FORM THE VALUE CHAIN ON THE KNOWLEDGE PUSH TECHNOLOGY PLATFORM OF THE LIBRARY AND INFORMATION INSTITUTIONS}

Carrying out a detailed analysis of the knowledge push technology platform of the Library and Information Institution from the point of value chain, a conclusion is drawn: the knowledge push technology platform of the Library and Information Institutions must be implemented and how to achieve its value. The implementation of the main frame of knowledge push technology service platform is divided into several parts: first, the various factors that affect the value realization mode of the knowledge push service platform, and these factors also serve as the premise if the knowledge push service platform can be implemented or not, including some aims, information management ideas, the knowledge resources and the main core competitiveness related to the Library and Information Institution, and including the various external environment and different situations that may be met during the implementation process of the knowledge push technology platform. Second, the value realization mode of knowledge push technology platform of Library and Information Institution. After the implementation of the knowledge push technology platform, in order to be able to achieve the purpose of business, it is necessary to clearly know how it is to achieve the value. This part is related to the various specific operations of the knowledge push technology platform of the Library and Information 
Institutions. Third, the various different factors which support the knowledge push technology platform of Library and Information Institutions. It can affect the normal operation of knowledge push technology platform such as the factor of the technology, talent, social resources, social needs and other factors. Fourth, carrying out renewal of technology and related aspects of the knowledge push technology platform timely. In the process of continuous development of Library and Information Institution, knowledge push service platform should do some adjustments and some assessments in order to promote the knowledge push service platform, and to promote themselves and improve themselves in the process of continuous development and improvement to better establish their own credibility and competitiveness.

There are many factors that affect the value of the knowledge push service platform, which can be divided into internal and external factors. In general, the impact on knowledge push technology platform implementation of the internal factors is relatively small, while the impact of external factors is much bigger; it is mainly to introduce some external factors which have impacts. External factors can be divided into two aspects: micro external factors and macro external factors. The market in a number of other professional technology services, competitors and some purchased mirror cooperation platform and some of its downstream business needs and other factors related to the new entrants are the micro external factors. The technology service market environment, information service industry environment and some technical and financial environment and other factors are macro external factors. The impact caused by external factors compared to the internal factors is reflected in, there is a very large probability to lead to the change of knowledge push technology platform when external factors once appear to change, and it can further affect the value realization mode of the knowledge push service platform, forcing it to make the corresponding adjustment. View from the value realization mode of knowledge push platform of the library and information institutions, purchased mirroring service and local talent resources such as combining the advantages of the new service model will affect the business model and the business strategy under the extension of knowledge push. Therefore, in order to realize the value of the research more conveniently and quickly, the business strategy and the management idea of the library and information institution should be matched with each other. It can also be said that the study of external resources, environment and capabilities, coupled with its main business model is the logical starting point for the realization of the value of knowledge push.

\section{The Process of VAlue Formation of THE KNOWLEDGE PUSH TECHNOLOGY PLATFORM OF LIBRARY AND INFORMATION INSTITUTIONS}

Value analysis, value network, value transmission, value proposition and value realization are five main parts in the process of value formation of knowledge push technology platform. They are not completely independent. Instead, they are interrelated, mutual penetrated and mutual influenced with each other, and constitute a more scientific system. Each part is equivalent to the subset of the system and cooperates with each other to create value.

It is called value analysis that the value of each part of the process of knowledge transfer process being analyzed, and the value of each part of the value formation process and the related industrial value being extended, and then grasping the economic benefits of the technology platform. At the same time, the emphasis of value analysis is the knowledge resources of Library and Information Institutions and its advantage in technology, and the value activity involved in the course of study is also able to influence the scope of knowledge push technology platform.

The specific task and requirement of knowledge push service is the value proposition of the knowledge push technology platform of Library and Information Institutions, and the way of providing knowledge products and services to customers with special requirements. But it is worth noting that the value proposition of knowledge push technology platform is based on the knowledge resources and the core competitiveness of their own, according to the different scope of management and some new knowledge value added services to achieve the purpose of innovation value. In obtaining value innovation is also a process of increasing and maintaining its own resources and core competitiveness. When the value proposition of the knowledge push technology platform is determined, it can be subdivided into the various internal departments of the library and information organizations, so that a clear value proposition can be realized in the practical operation.

In the premise of realizing the value of the knowledge push technology platform, the value of the resources is realized by some scientific and reasonable project management and some management structure adjustment to realize the value added products, and this is called value network. Although the knowledge service provided by the library and information service is not a service for the purpose of profit, it is mainly provided by public knowledge retrieval service, but the value chain of knowledge push is able to construct the value network of knowledge resources. Various types of knowledge resources will be re integrated, so that the original value of knowledge can be re added additional value-added output. Knowledge resources that can be added to the output of the specific terms of the main including some of the main core competitiveness, professional knowledge, technical resources, but also some of the relevant government policies such as trademarks, fixed market, etc.. A scientific and reasonable value network is a guarantee for the transmission of higher efficiency value in terms of knowledge push technology platform.

The process of interaction within the information related to the creating value between the upstream and downstream of the value chain is called value transmission. In the study of the value chain, we need to separate the various parts of the value chain, each link is carefully analyzed, and the value of information transmission needs to be carried out in order to guarantee the value of each link, the purpose is to ensure 
that the knowledge push technology platform can be orderly and reasonable operation through each link. Through the integration of the whole value chain, the economic benefits of the whole value chain can be amplified through the integration of every detail. This kind of value transmission way can not only make the whole value chain of economic benefit to expand, but also to take care of the value of each part of the value of the benefit. So, in the process of carrying out the knowledge push technology platform of Library and information institutions, the value chain is the evaluation criteria of the mutual relationship and project value. It is able to carry out the whole knowledge push technology platform.

A important reference standard if the value of knowledge push technology platform is achieved is value realization. For this research point, it means that the details of the initial knowledge and value added services that can be provided in the process of knowledge push and the value chain are selected. For the entire knowledge push service platform, the first is construction period, the knowledge push process of some of the knowledge needs to be carefully analyzed, and some knowledge of the collection and integration; the next is the operation period, at this time knowledge push service platform is start to carry out the knowledge of the needs of the information and the knowledge of certain packaging, etc., in order to let the knowledge push technology platform can be improved, so that the service quality can be improved through some evaluation and feedback and so on. When each link in the value chain can achieve the value of the whole platform to achieve revenue, you can let the knowledge push the value chain to accelerate the pace of. From the point of view of the value of the knowledge push technology platform, it not only involves the knowledge service with higher professional knowledge, but also the strong knowledge value added service. And for the library and information institution knowledge push technology platform can realize the measure of its value is also through the comparison system and the interrelated value chain to achieve.

\section{WhAT IS THE SUPPORT OF THE KNOWLEDGE \\ Push TECHNOLOGY PLATFORM OF LIBRARY AND INFORMATION INSTITUTIONS?}

Like any material is not independent existence, the realization mode of any value is not independent, in the construction of knowledge push service platform, and its future business management, the normal and effective operation of knowledge push technology platform will be affected by many factors, these factors in the operation of the technical platform also supports the entire knowledge service process. Because the knowledge push technology platform involves a wide range of knowledge, such as information technology consulting, numerical library literature class service and a variety of knowledge services, etc., so that the value of the operating management of Library and information institutions should have a higher level of knowledge and expertise to integrate the ability and some knowledge of professional value-added services. And in the realization of the value of each part of it are likely to be affected by different factors, but these factors are not independent existence, there is still a certain link or some common features, such as some of the cultural characteristics of the study, its human, intellectual resources and some technical level, etc..

\section{The Operative Mode OF UPDATING THE KNOWLEDGE PUSH TECHNOLOGY PLATFORM OF LIBRARY AND INFORMATION INSTITUTIONS TIMELY}

The operation mode of any organization is not fixed, but the model is always dynamic and there is a certain complexity. Under the environment that the professional information service industry in our country obtain a rapid development in the Sci-Tech Novelty Retrieval Institution, but also to promote the knowledge of Library and information institutions to push technology platform to change the main way, and gradually improve. In addition, through the feedback and evaluation mechanism of the knowledge push technology platform itself, it can also adjust the self and to carry out the change of the relevant policies. Therefore, in the possession of knowledge push platform technology business operation conditions, knowledge services of Library and information institutions can also in the process of knowledge push incidentally is its internal efficiency is greatly improved and external competitiveness can also greatly improved, at the same time also can corresponding to improve its service scope and its service value.

\section{CONCLUSIONS}

In the context of informatization and networked, the demand for knowledge is becoming increasingly urgent, but there is the situation that the utilization of knowledge is not high but and the wanted knowledge cannot be found. Therefore, the knowledge push technology platform of the Library and Information Institution which comes into being in this environment has provided a good solution to this situation, and it has shed a light on its future development.

\section{REFERENCES}

[1] ZHANG Liping. The Competitive Strategy of Library and Information Institutions under the Network Environment.[J]. Shanxi Science and Technology. 2005 (06)

[2] XU Suquan, XIONG Sanlu. On the Application of Micro Blog in the Library and Information Institutions.[J]. Science and Technology Management Research. 2011 (22)

[3] XU Hua, MA Yingzhi, ZHANG Yibo. Overview of Library and Information Services under the New Situation.[J]. Private Technology. 2013 (01)

[4] DENG Dehao. Issues and Countermeasures of Human Resource Management in Library and Information Institutions.[J]. Journal of Hubei Normal University (NATURAL SCIENCE EDITION). 2007 (02)

[5] DANG Yuewu, ZHANG Xiaolin, LI Guihua, Developing the Environment which is Beneficial to the Development of Library and Information Services. [J]. Library.2001 (06)

[6] DANG Yuewu, ZHANG Xiaolin, LI Guihua. Developing the Modern Management Mechanism of the Library and Information Institution which supports knowledge service.[J]. Chinese Library Journal.2001 (01)

[7] LI Suzhen, GE Baohua. The Application of Knowledge Management in Library and Information Institutions.[J]. Hebei Journal of Social Sciences (SOCIAL SCIENCE EDITION). 2003 (03) 
[8] ZHANG Shuping. Changes in the Organization and Management Mechanism of the Library and Information Institution.[J]. Journal of Shenyang Normal University (SOCIAL SCIENCE EDITION). 2004 (04)

[9] GUO Shufang. The Sustainable Development of Library and Information Institutions Management and Service Mode,
Knowledge Management and Knowledge Service.[J]. Journal of Lanzhou. 2004 (05)

[10] LI Suzhen, GE Baohua. Application of Knowledge Management in Library and Information Institutions.[J]. Hebei Journal of Social Sciences (SOCIAL SCIENCE EDITION). 2003 (03) 